\section{PROPUESTA METODOLÓGICA PARA MEDIR LA RESILIENCIA URBANA ANTE HURACANES E INUNDACIONES EN EL CARIBE MEXICANO}

José Manuel Camacho Sanabria ${ }^{1,2, *}$, Rosalía Chávez Alvarado ${ }^{1,2}$ y David Velázquez Torres ${ }^{1}$

\section{RESUMEN}

EI Caribe Mexicano es una de las áreas geográficas amenazadas por los efectos del cambio climático, sobre todo por huracanes e inundaciones que cada vez son más frecuentes e intensas. Ante esto, resulta importante conocer las condiciones de resiliencia de la población que habita en las ciudades costeras de Quintana Roo, principalmente en Chetumal, Tulum y Playa del Carmen, ciudades con altas tasas de crecimiento poblacional a nivel estatal, las cuales se encuentran incluso por encima del promedio anual nacional. El presente estudio propone una metodología aplicada para recopilar información sobre los componentes de la resiliencia ante huracanes e inundaciones de las ciudades referidas. El desarrollo de la propuesta se llevó a cabo mediante dos fases: la primera consistió en la revisión exhaustiva de bibliografía sobre resiliencia urbana a nivel internacional, nacional y local para la construcción de un modelo conceptual. La segunda se enfocó a la aplicación de 972 encuestas: 450 se realizaron en Chetumal, 344 en Playa del Carmen y 178 en Tulum. Con esta metodología los costos del trabajo de campo se redujeron, el tiempo de aplicación de las encuestas se optimizó y la compilación de información fue exitosa.

\section{PALABRAS CLAVE}

Resiliencia urbana, Huracanes, Inundaciones, Metodología, Caribe Mexicano

\section{METHODOLOGY FOR HURRICANE AND FLOODS URBAN RESILIENCE IN THE MEXICAN CARIBBEAN}

\section{ABSTRACT}

The Mexican Caribbean is one of the regions most threatened by the effects of climate change, especially by hurricanes and floods that are becoming more frequent and intense. Therefore, it is important to assess the resilience conditions of the population living in the coastal cities of Quintana Roo, mainly in Chetumal, Tulum and Playa del Carmen, which are cities with high rates of population growth at national level. This study examines an applied methodology for data collection on specific components of urban resilience to hurricanes and floods. Data collection was carried out through two phases. The first consisted in an exhaustive literature review on urban resilience at international, national and local levels, from which a conceptual model was developed. The second focused on the application of 972 surveys: 450 were conducted in Chetumal, 344 in Playa del Carmen and 178 in Tulum. With this methodology, fieldwork costs were reduced, time was optimized, and the compilation of information was successful.

\section{KEYWORDS}

Urban resilience, Hurricanes, Floods, Methodology, Mexican Caribbean
1. Unidad Académica Chetumal, División de Ciencias e Ingeniería, Universidad de Quintana Roo, Chetumal, México.

2. Cátedra CONACYT Universidad de Quintana Roo, Chetumal, México.

*Autor de correspondencia: jmanuelcs@live.com.mx

\section{RECIBIDO}

10 de febrero de 2019

\section{ACEPTADO}

o2 de mayo de 2019

\section{PUBLICADO}

1 de julio de 2019

\section{Formato cita}

Recomendada (APA):

Camacho Sanabria, J.M.,

Chávez Alvarado, R. \& Velázquez Torres, D. (2019). Propuesta Metodológica para medir la Resiliencia Urbana ante Huracanes e Inundaciones en el Caribe Mexicano. Revista de Estudios Latinoamericanos sobre Reducción del Riesgo de Desastres REDER, 3(2), 28-43.

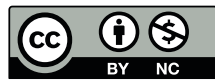

Todos los artículos publicados en REDER siguen una política de Acceso Abierto y se respaldan en una Licencia CreativeCommons Atribución-NoComercial 4.0 Internacional.

Revista de Estudios

Latinoamericanos sobre Reducción del Riesgo de Desastres (REDER)

Diseño: Lupe Bezzina Tipografía: Hospital 


\section{INTRODUCCIÓN}

Los efectos del cambio climático son cada vez más notorios debido a la magnitud y frecuencia con que ocurren, situación que preocupa a los tomadores de decisiones y a los especialistas en el tema, sobre todo porque ocasionan desastres que se traducen en pérdidas económicas y humanas significativas. Según el Panel Intergubernamental del Cambio Climático (IPCC, 2014) las principales amenazas globales derivadas del cambio climático (tormentas tropicales, inundaciones, crecimiento del nivel del mar, clima extremo, olas de calor) se van a concentran en las áreas urbanas más pobladas. De hecho, la preocupación por la exposición al riesgo y por la vulnerabilidad de las ciudades ante las amenazas naturales ha ido en aumento en las últimas décadas, debido a que son espacios con una elevada densidad de población, concentran servicios e infraestructuras y activos económicos; además se consideran el motor económico de la mayoría de los países (Galceran, 2015).

México es uno de los países más vulnerables a los efectos del cambio climático, las características geográficas que lo describen hacen posible esto. Su localización entre dos océanos, así como su latitud y condiciones fisiográficas contribuyen a que sea un territorio particularmente expuesto a diferentes fenómenos hidrometeorológicos. Un análisis de cambio en la frecuencia de ocurrencia de huracanes que afectaron el territorio mexicano durante el periodo 1970-2009 reporta un incremento, en especial de aquellos de alta intensidad (categoría 3, 4 y 5) en el Golfo de México y el Mar Caribe. En este periodo el Atlántico mexicano fue impactado por 264 ciclones tropicales, y el Pacífico por 549 (Comisión Intersecretarial de Cambio Climático, 2012).

En 2012 México publicó la Ley General de Cambio Climático que prevé dos instrumentos fundamentales para orientar e instrumentar la política pública en la materia. El primero de ellos, de mediano y largo plazo es la Estrategia Nacional de Cambio Climático y el segundo, de corto plazo es el Programa Especial de Cambio Climático 2013-2018. Este último, tiene como principal propósito reducir la vulnerabilidad de la población, de los ecosistemas y sectores productivos e incrementar su resiliencia y la resistencia de la infraestructura estratégica (Secretaría de Medio Ambiente y Recursos Naturales, 2014). Otro de los instrumentos que contempla acciones de prevención, fortalecimiento y recuperación ante los efectos del cambio climático es la nueva Ley General de Asentamientos Humanos, Ordenamiento Territorial y Desarrollo Urbano que fortalece las bases para la gestión de riesgos en los asentamientos humanos.

Aunado a lo anterior, existen iniciativas nacionales recientes que se han elaborado con el objetivo de disminuir la vulnerabilidad e incrementar la resiliencia ante el impacto de múltiples y diversas amenazas. En atención al Programa de Perfiles de Ciudades Resilientes (CRPP, por sus siglas en inglés), la Secretaría de Gobernación (SEGOB), en conjunto con la Secretaría de Desarrollo Agrario, Territorial y Urbano (SEDATU) implementaron la Red de Ciudades Resilientes para México, conformada por 18 ciudades distribuidas en 17 estados del país, entre las cuales destaca la ciudad de Playa del Carmen, ubicada en el municipio de Solidaridad, Quintana Roo. Como complemento, y con el propósito de cumplir con los compromisos del desarrollo sostenible establecidos en Hábitat III, SEDATU y la SEGOB, a través de la Coordinación General de Protección Civil de México y ONU - Hábitat, elaboraron la Guía de Resiliencia para fortalecer y orientar a los gobiernos locales a prevenir, enfrentar y responder de manera inmediata a los desastres. Este instrumento fue diseñado para ser utilizado por las autoridades municipales que conforman al país y describe la metodología para obtener el Perfil de Resiliencia Urbana de cada región (ONU - Hábitat, 2017).

Reportes de la National Oceanic and Atmospheric Administration (NOAA) muestran que en la costa caribeña de México se han registrado 614 eventos meteorológicos extremos (desde tormentas tropicales hasta huracanes categoría 5 en escala de Saffir-Simpson) desde 1949 hasta 2005. La mayor frecuencia e intensidad de tales eventos durante las últimas décadas se ha vinculado al cambio climático (Vidal, 2010), razón por la cual especialistas en la temática han realizado propuestas orientadas a la generación de programas de adaptación ante la variabilidad climática y el cambio climático del sector turismo en la Rivera Maya de Quintana Roo. Estas iniciativas contribuyen a articular y orientar los instrumentos de política pública y las acciones necesarias para reducir la vulnerabilidad, fortalecer las capacidades de adaptación de la sociedad y aumentar la resiliencia (Academia Nacional de Investigación y Desarrollo, 2013a, 2013b, 2013c).

La Ley de Asentamientos Humanos, Ordenamiento Territorial y Desarrollo Urbano del Estado de Quintana Roo establece, en materia de riesgo y resiliencia, que se deben determinar las normas 
básicas para la prevención de riesgos y contingencias en los asentamientos humanos, tendiente a garantizar la seguridad y protección civil de sus habitantes y bienes. Además, se debe propiciar y fortalecer todas las instituciones y medidas de prevención, mitigación atención, adaptación y resiliencia que tengan por objetivo proteger a las personas y su patrimonio, frente a los riesgos naturales y antrópicos, así como evitar la ocupación de zonas de alto riesgo (H. Congreso del Estado de Quintana Roo, 2018).

A pesar de los esfuerzos realizados en la implementación de las iniciativas referidas, aún existen áreas de oportunidad que se intentaron incluir en este trabajo. Se consideraron variables relacionadas con la amenaza (huracán e inundaciones), sociales, económicas, de la vivienda, institucionales y culturales, sustentadas en un modelo conceptual propuesto. Además se actualizó la información geoespacial a nivel local (ciudad), la cual contribuyó a la construcción de indicadores e índices para el desarrollo de acciones orientadas al incremento de la resiliencia. Esto fue posible mediante la elaboración de una encuesta diseñada para entender la percepción de la sociedad ante la atención y recuperación tras el impacto de un huracán e inundación, obteniendo indicadores que los actores clave de gobierno y organizaciones sociales y civiles mencionaron requerir para mejorar sus acciones ante la gestión del riesgo de desastres a nivel de ciudades.

El presente estudio comprende los acuerdos internacionales en materia de prevención y mitigación de desastres, así como las iniciativas que contribuyen al incremento de la resiliencia en áreas urbanas. En una segunda instancia se describen algunas características del área de estudio, así como la metodología aplicada en este trabajo. También se muestra el modelo conceptual propuesto en el cual se sustentó la encuesta, así como los mapas del diseño de muestreo, el plan de trabajo de campo y los resultados derivados de la encuesta.

\section{MARCO REFERENCIAL}

El carácter global que implican los desastres ha motivado a distintos especialistas en el tema a desarrollar e implementar iniciativas e instrumentos orientados a la prevención y mitigación de los desastres, así como al incremento de la resiliencia de las naciones y comunidades ante el impacto de los mismos. Durante el periodo 1990-1999 se propone la iniciativa Decenio Internacional para la Reducción de los Desastres Naturales, cuyo principal fin era disminuir los desastres a través de una mayor vigilancia y conocimiento sobre las amenazas naturales, desde el punto de vista científicotécnico (Lavel, 1997). Esta iniciativa contribuyó a la formación de la Red de Estudios Sociales en Prevención de Desastres en América Latina (La RED), organización conformada por múltiples y diversas instituciones y profesionales del continente americano como respuesta a la necesidad de estimular y fortalecer el estudio social del riesgo y definir, a partir de ello, nuevas formas de intervención y gestión orientadas a la prevención y mitigación del riesgo.

A mitad del decenio, en el marco de la Conferencia Mundial sobre la Reducción de los Desastres Naturales, agrupaciones nacionales, regionales e internacionales de 155 países y territorios examinaron las medidas que la comunidad científica, los gobiernos nacionales, los organismos regionales y las organizaciones internacionales elaboraron a inicios del decenio para prevenir y mitigar los desastres. Este análisis, así como las orientaciones para el porvenir quedaron recapituladas en el Mensaje, Estrategia y Plan de Acción de Yokohama para un Mundo más Seguro (Naciones Unidas, 1994). Esto fue el referente para que se promovieran acciones más concretas sobre la disminución de riesgos, las cuales fueron plasmadas en el Marco de Acción de Hyogo para 2005-2015: Aumento de la resiliencia de las naciones y comunidades ante los desastres, documento que describe los desastres causados por amenazas de origen natural y los desastres y riesgos ambientales y tecnológicos conexos; refleja un enfoque integral de la gestión del riesgo de desastres que prevé amenazas múltiples y la posible relación entre ellos, que puede tener importantes consecuencias en los sistemas sociales, económicos, culturales y ambientales que se subrayan en la Estrategia de Yokohama (Naciones Unidas, 2005).

Derivado de estas reuniones, México comenzó a instrumentar acciones para atender los compromisos internacionales relacionados con la disminución de riesgos ambientales en ámbitos urbanos. Una de las principales acciones fue la consulta y revisión de las leyes nacionales sobre medio ambiente, ordenamiento territorial y riesgos, que era evidente se encontraban desvinculadas de los acuerdos internacionales y, desde luego, de la realidad del país.

En 2010, la Oficina de las Naciones Unidas para la Reducción del Riesgo de Desastres (UNISDR, por sus siglas en inglés) instrumentó la Campaña Mundial "Desarrollando Ciudades Resilientes 
- ¡Mi ciudad se está preparando!", cuyo objetivo era fomentar y aumentar el compromiso de los gobiernos locales y nacionales para que la reducción de riesgos y la resiliencia a los desastres y al cambio climático sea una prioridad de sus políticas, y valerse del Marco de Acción de Hyogo para abordar más de cerca las necesidades locales (Naciones Unidas, 2012). En México comenzaron a implementarse las acciones implícitas en esta campaña, principalmente en las ciudades de México, Cancún y Guadalajara; esta última incluyó acciones sobre resiliencia en su plan de desarrollo urbano metropolitano, además se consideró una ciudad modelo a seguir a nivel nacional.

El Marco de Sendai para la Reducción del Riesgo de Desastres 2015-2030 se aprobó en 2015, instrumento sucesor del Marco de Acción de Hyogo, que sigue reconociendo el objetivo de reducir todo tipo de pérdidas causadas por los desastres. El Marco de Sendai expresa la necesidad de comprender mejor el riesgo de desastres en todas sus dimensiones relativas a la exposición, la vulnerabilidad y características de las amenazas de cada área geográfica, cómo fortalecer la gobernanza desde la perspectiva del riesgo de desastres, realizar la rendición de cuentas (transparente) sobre los presupuestos de atención al riesgo, plantear acciones para reconstruir mejor, aumentar las investigaciones sobre resiliencia de la infraestructura crítica, incrementar las alianzas entre países para el apoyo dirigido a la atención, recuperación y reconstrucción tras un desastre, así como la elaboración y modificación de políticas enfocadas a realizar la gestión del riesgo de manera eficaz y eficiente (Naciones Unidas, 2015).

En estos últimos años han surgido otras iniciativas orientadas a concientizar y preparar a las ciudades para la construcción de la resiliencia ante los desafíos sociales, económicos y físicos a los que deberán enfrentarse en un mundo cada vez más urbanizado. Entre ellas destacan: a) el Desafío 100 Ciudades Resilientes de la Rockefeller Fundation que, aparte de dar asistencia para el desarrollo de una estrategia de resiliencia, busca fomentar que todas las ciudades cuenten con un Director Ejecutivo de Resiliencia y b) el Programa de Perfiles de Ciudades Resilientes (CRPP, por sus siglas en inglés) de ONU - Hábitat, que tiene como objetivo general aportar las herramientas necesarias para que las ciudades estén mejor preparadas para afrontar crisis, como los desastres, que afecten su funcionamiento y estructura (Galceran, 2015). Esto mediante la creación de un enfoque de planificación y gestión urbana amplio e integrado.

En octubre de 2016 se aprobó la Nueva Agenda Urbana en el marco de la Conferencia de las Naciones Unidas sobre la Vivienda y el Desarrollo Urbano Sostenible (Hábitat III). Este instrumento representa un ideal común para lograr un futuro mejor y más sostenible, en el que todas las personas gocen de igualdad de derechos y de acceso a los beneficios y oportunidades que las ciudades pueden ofrecer, y en el que la comunidad internacional reconsidere los sistemas urbanos y la forma física de nuestros espacios urbanos como un medio para lograrlo. También pretende fortalecer la resiliencia urbana, reduciendo los riesgos de desastre e implementando medidas de adaptación al cambio climático y mitigación de sus efectos (Naciones Unidas, 2017). Ante este contexto, México modificó la Ley General de Asentamientos Humanos el 2016, instrumentando acciones que contribuyeran a que las ciudades sean resilientes, desde luego, fortaleciendo las limitaciones para el crecimiento urbano en áreas no aptas para su desarrollo. Sin embargo, aún es un documento limitado para lograr frenar las fuerzas del mercado inmobiliario que controlan las expansiones territoriales sin considerar los riesgos e impactos ambientales que ocasionan.

Por otro lado, la resiliencia es un parámetro de naturaleza multifacética, multidimensional, altamente dinámico, por tanto, difícil de parametrizar, cuantificar y valorar (Torrico y Jansses, 2010). Medir la resiliencia sin un marco conceptual robusto puede llevar a interpretaciones ambiguas y aisladas (Smith et al., 2016), en el mejor de los casos un marco conceptual debe incluir la dinámica del tiempo y hacer referencia a eventos perturbadores del sistema (Janssens et al., 2015). Los estudios sobre resiliencia escasamente mencionan el trabajo de las instituciones, la respuesta de los gobiernos locales y las personas afectadas; están limitados los datos que evidencian procesos adaptativos de la población, de las instituciones y marcos regulatorios, así como la falta de coordinación entre gobiernos y sus objetivos en la gestión del riesgo (Adger et al., 2005; Grothmann y Patt, 2005).

Para este estudio se consideró el concepto de resiliencia de la UNISDR (2009), que la define como la capacidad de un sistema, comunidad o sociedad expuesta a una amenaza para resistir, absorber, adaptarse y recuperarse de sus efectos de manera oportuna y eficaz, esto incluye la preservación y restauración de sus estructuras y funciones básicas. Las ciudades, como sistemas complejos adaptativos, se consideran resilientes toda vez que tengan la capacidad de recuperarse 
aceleradamente ante los impactos adversos que sufren sus componentes. Esta definición se basa en la concepción de la urbe como un sistema de sistemas, un ente complejo que requiere del buen funcionamiento de los distintos componentes que lo integran, para lograr la sostenibilidad (Fernández, 2015). Ante los efectos del cambio climático y el proceso de urbanización acelerado, resulta importante y apremiante transformar las ciudades y comunidades en sistemas resilientes.

La resiliencia está constituida por tres capacidades clave: la absorción, adaptación y transformación (Jacobi et al., 2014; Jeans et al., 2017). La capacidad adaptativa es parte de las propiedades de la resiliencia, debido a que ésta se relaciona con la gestión y gobernanza de los cambios de un sistema para mejorar su relación con el ambiente. En México, desde la década de los setenta, las ciudades constituyen sistemas complejos adaptativos, debido a que se expandieron en zonas no aptas para su desarrollo, afectando diversos ecosistemas, reemplazando las áreas destinadas a la producción agrícola; la relación entre sus ciudades es distinta, jerárquica, con un desarrollo de su proceso de adaptación menor al de otras urbes. Las ciudades costeras mexicanas también están experimentando procesos complejos adaptativos, debido a las tasas de crecimiento explosivas que registran y a los sistemas sociales, económicos y políticos que atentan con su ambiente; esta situación provoca que estos espacios sean altamente vulnerables ante la ocurrencia de fenómenos hidrometeorológicos

Considerando lo anterior, fue necesario elaborar un instrumento de recolección de información sobre resiliencia urbana costera ante huracanes e inundaciones, con el propósito de construir una base de datos confiable que sirva de referente para el diseño de acciones y la toma de decisiones en las ciudades del Caribe Mexicano, principalmente las que han registrado un crecimiento demográfico acelerado y excesivo en la última década (Chetumal, Tulum y Playa del Carmen).

\section{ÁREA DE ESTUDIO}

La aplicación de la encuesta se llevó a cabo en las ciudades costeras de Chetumal, Tulum y Playa del Carmen, ubicadas en el estado de Quintana Roo, específicamente en la porción sureste del territorio que comprende la República Mexicana (Figura 1). La selección de estos casos de estudio se sustenta en el incremento exponencial demográfico que han experimentado en la última década (2000-2010). Chetumal registró una tasa de crecimiento promedio anual de $2.2 \%$, Tulum $10.1 \%$ y Playa del Carmen $12.7 \%$. Estos valores se encuentran por encima de la tasa de crecimiento anual nacional de $1.4 \%$ (INEGI, 2013).
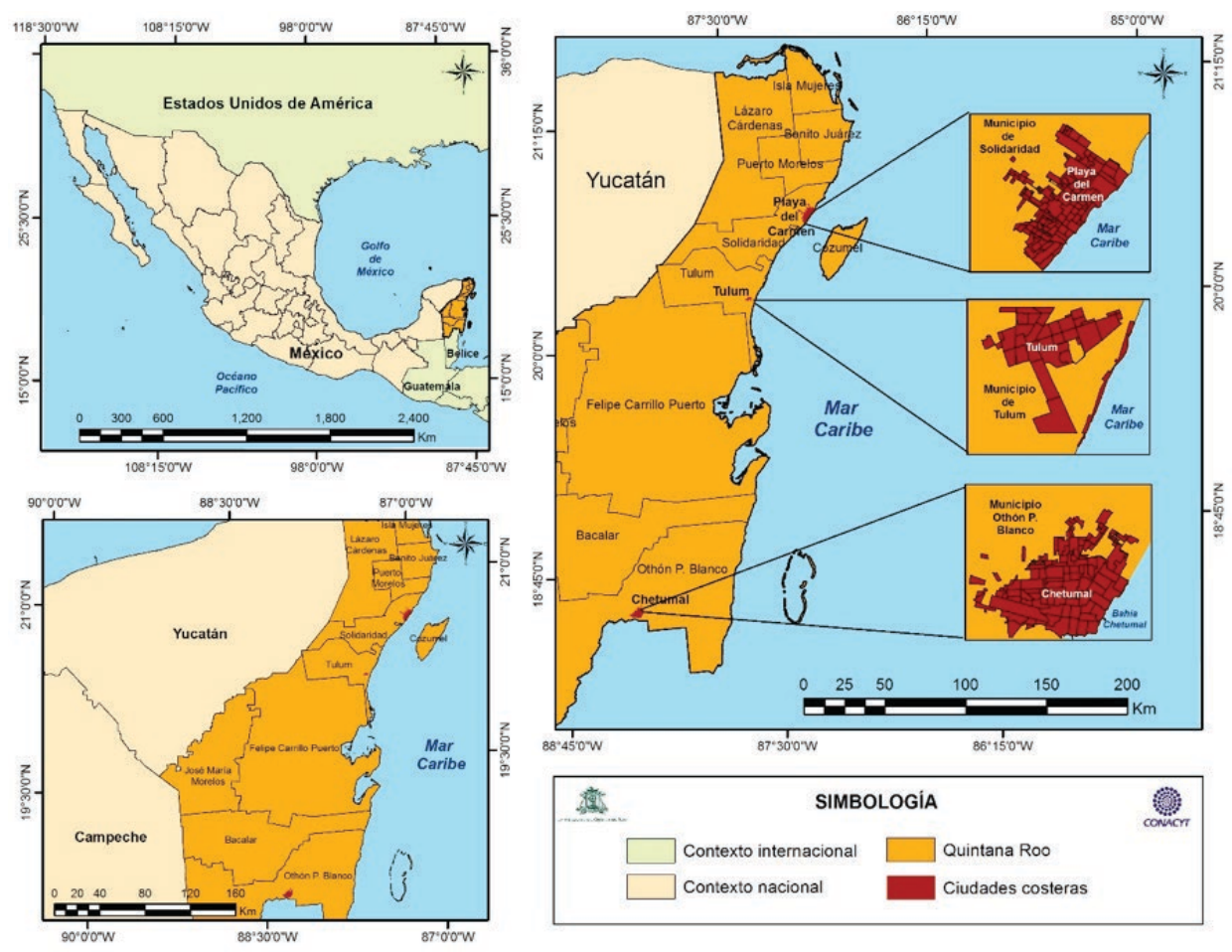

Figura 1. Ubicación geográfica del área de estudio en el contexto nacional, regional y estatal Fuente: Autores, 2019, con base en INEGI (2016). 
La alta exposición al riesgo de desastres por huracanes e inundaciones de estas ciudades fue otro de los criterios a considerar. De acuerdo con Ihl y Frausto (2014), entre 1866 y 2007 se han registrado 40 huracanes de distintas magnitudes que han afectado al estado de Quintana Roo, principalmente a las ciudades costeras.

\section{METODOLOGÍA}

Previo al diseño y elaboración de la encuesta se propuso un modelo conceptual de 'resiliencia urbana costera ante huracanes e inundaciones' con base en la consulta y revisión de documentos asociados con el tema (Gallopín, 2006; Cutter et al., 2008; Norris et al., 2008; Resilience Alliance, 2010; Cutter et al., 2014; CONRED, 2015; Rockefeller Fundation-Arup, 2015; Parsons et al., 2016; SEDATU, 2016) y mediante talleres participativos. A partir de este modelo se determinaron las variables para el cálculo de indicadores referentes a los componentes de la resiliencia urbana costera (amenaza, vulnerabilidad y capacidad de adaptación). La información correspondiente a las variables se obtuvo a través de un instrumento de recolección de datos, el cual se elaboró con base en la encuesta de Sierra (2014). Los principales criterios que se consideraron para su integración fueron la pertinencia, relevancia y claridad (incluyendo el lenguaje local) de los cuestionamientos. La encuesta fue revisada por un grupo de expertos (investigadores y estudiantes) y actores clave que colaboran en la gestión del riesgo de desastres; además fue validada mediante la aplicación de una prueba piloto. Los principales cuestionamientos que se replantearon fueron los correspondientes a los ambientes construido y cultural (Tabla 1).

\begin{tabular}{|c|c|}
\hline Bloque & Descripción \\
\hline 1. Datos de control & $\begin{array}{l}\text { Hacen referencia a la fecha y hora de aplicación, nombre del } \\
\text { encuestador y el número de folio de la encuesta. }\end{array}$ \\
\hline 2. Datos de identificación de la vivienda & $\begin{array}{l}\text { Es información referente a la ubicación de la vivienda (ciudad, } \\
\text { número de Área Geoestadística Básica [AGEB], número de } \\
\text { manzana, nombre de la colonia y calle y número de lote y/o } \\
\text { predio). }\end{array}$ \\
\hline 3. Conocimientos previos & $\begin{array}{l}\text { Son cuestionamientos orientados al conocimiento que tienen } \\
\text { las personas respecto a los términos riesgo, vulnerabilidad y } \\
\text { resiliencia. }\end{array}$ \\
\hline 4. Ambiente social & $\begin{array}{l}\text { Corresponden a la edad, sexo, estado civil, años de residencia en } \\
\text { la ciudad y vivienda del entrevistado, número de integrantes de } \\
\text { su familia, acceso a servicios de salud y aspectos educativos de } \\
\text { los integrantes de la familia, entre otros. }\end{array}$ \\
\hline 5. Ambiente económico & $\begin{array}{l}\text { Comprenden la ocupación del jefe del hogar, número de inte- } \\
\text { grantes de la vivienda que trabajan y su ocupación y los gastos } \\
\text { destinados al hogar. }\end{array}$ \\
\hline 6. Ambiente construido & $\begin{array}{l}\text { Se refieren a las características de la vivienda, como tipo, ma- } \\
\text { teriales de construcción, número de cuartos y pisos o niveles, } \\
\text { superficie, medios de adquisición, servicios básicos, bienes o } \\
\text { enseres domésticos, cuenta con seguro ante desastres, entre } \\
\text { otros. }\end{array}$ \\
\hline 7. Ambiente institucional & $\begin{array}{l}\text { Corresponden a las acciones preventivas, de mitigación y } \\
\text { respuesta que han implementado las autoridades ante la } \\
\text { ocurrencia de un huracán o inundación. También se consideran } \\
\text { los servicios que brindan a la población, como recolección de } \\
\text { residuos sólidos y agua, principalmente. }\end{array}$ \\
\hline 8. Ambiente cultural & $\begin{array}{l}\text { Hacen referencia a los conocimientos adquiridos e implemen- } \\
\text { tados a través de las experiencias vividas ante huracanes } \\
\text { o inundaciones ocurridos en la ciudad que residían o viven } \\
\text { actualmente. }\end{array}$ \\
\hline
\end{tabular}

Tabla l. Estructura y contenido de la encuesta Fuente: Autores, 2019. 
Se realizó un diseño del muestreo donde las unidades de muestreo fueron las viviendas particulares habitadas ubicadas en una determinada manzana y, al mismo tiempo, en un Área Geoestadística Básica (AGEB). Las viviendas particulares habitadas localizadas en zonas residenciales fueron excluidas del muestreo debido a la dificultad de acceso a éstas. El tamaño de la muestra se calculó a partir de la siguiente expresión matemática (Castillo, 2009):

$$
n=\frac{k^{2} * q * d}{r^{2} * p *(1-t)}
$$

Donde: $n=$ Tamaño de la muestra; $p=$ Porcentaje de población de 18 años y más sin educación pos-básica en la localidad urbana (INEGI, 2010); $q=1-p ; k=$ Nivel de confianza $(90 \%) ; r=$ Error relativo máximo (10\%); $d=$ Efecto del diseño (2.0); y $t=$ Tasa de no respuesta (15\%). Estos dos últimos valores se retomaron de la Encuesta Intercensal del INEGI (2015).

Previo a la selección de las unidades de muestreo fue necesario excluir las AGEBs que no registraron población ni viviendas particulares habitadas. Las AGEBs seleccionadas se agruparon a través del método multivariado Análisis por Conglomerados con $\mathrm{K}$ medias (Lagares y Puerto, 2001), La conformación de los estratos se realizó a partir de la selección de variables asociadas a los componentes de la resiliencia (vulnerabilidad y capacidad de adaptación), esto con la finalidad de diferenciar las disimilitudes socioeconómicas y culturales existentes entre las unidades de muestreo, así como su homogeneidad dentro de ellas (Tabla 2).

\begin{tabular}{ll} 
Variable & Componente \\
\hline Población no económicamente activa & Vulnerabilidad \\
\cline { 1 - 2 } Población de 5 años y más que hablan alguna lengua indígena & Capacidad de adaptación \\
\hline Hogares censales con jefatura femenina & \\
\hline Población derechohabiente a servicios de salud & \\
\hline Viviendas particulares habitadas con drenaje
\end{tabular}

Tabla 2. Variables para la conformación de estratos Fuente: Autores, 2019, con base en INEGI (2010).

El tamaño de la muestra se determinó para cada estrato aplicando el principio de distribución proporcional respecto a su tamaño. También se obtuvo el número de viviendas particulares habitadas a encuestar para cada AGEB a partir de este principio y considerando el tamaño de la muestra calculado. El número de viviendas a encuestar se ajustó al número par superior más próximo al calculado y el tamaño de la muestra ajustado se dividió entre dos para obtener el total de manzanas (Unidades Primarias de Muestreo) a encuestar en cada AGEB y éstas fueron seleccionadas a través del método aleatorio simple. En cada manzana se seleccionaron dos viviendas particulares habitadas (Unidades Secundarias de Muestreo) mediante el método de muestreo sistemático.

Previo a la aplicación de la encuesta se realizó un taller de capacitación dirigido a los encuestadores y coordinadores de campo, esto con la finalidad de socializar el cuestionario, sugerir estrategias que contribuyen a recopilar de manera eficiente la información y optimizar el tiempo de aplicación, conformar los equipos de trabajo, y planificar detalladamente las actividades de cada grupo de trabajo. La siguiente figura representa las etapas metodológicas del diseño y elaboración del instrumento de recolección de datos (encuesta) que comprende los componentes de la resiliencia urbana costera ante huracanes e inundaciones en el Caribe Mexicano (Figura 2).

En Chetumal se aplicaron un total de 450 encuestas distribuidas espacialmente en 225 manzanas y 98 AGEBs, para Tulum fueron 178 encuestas en 89 manzanas y 17 AGEBs y para Playa del Carmen se aplicaron 344 encuestas en 172 manzanas y 100 AGEBs (Figura 3). 


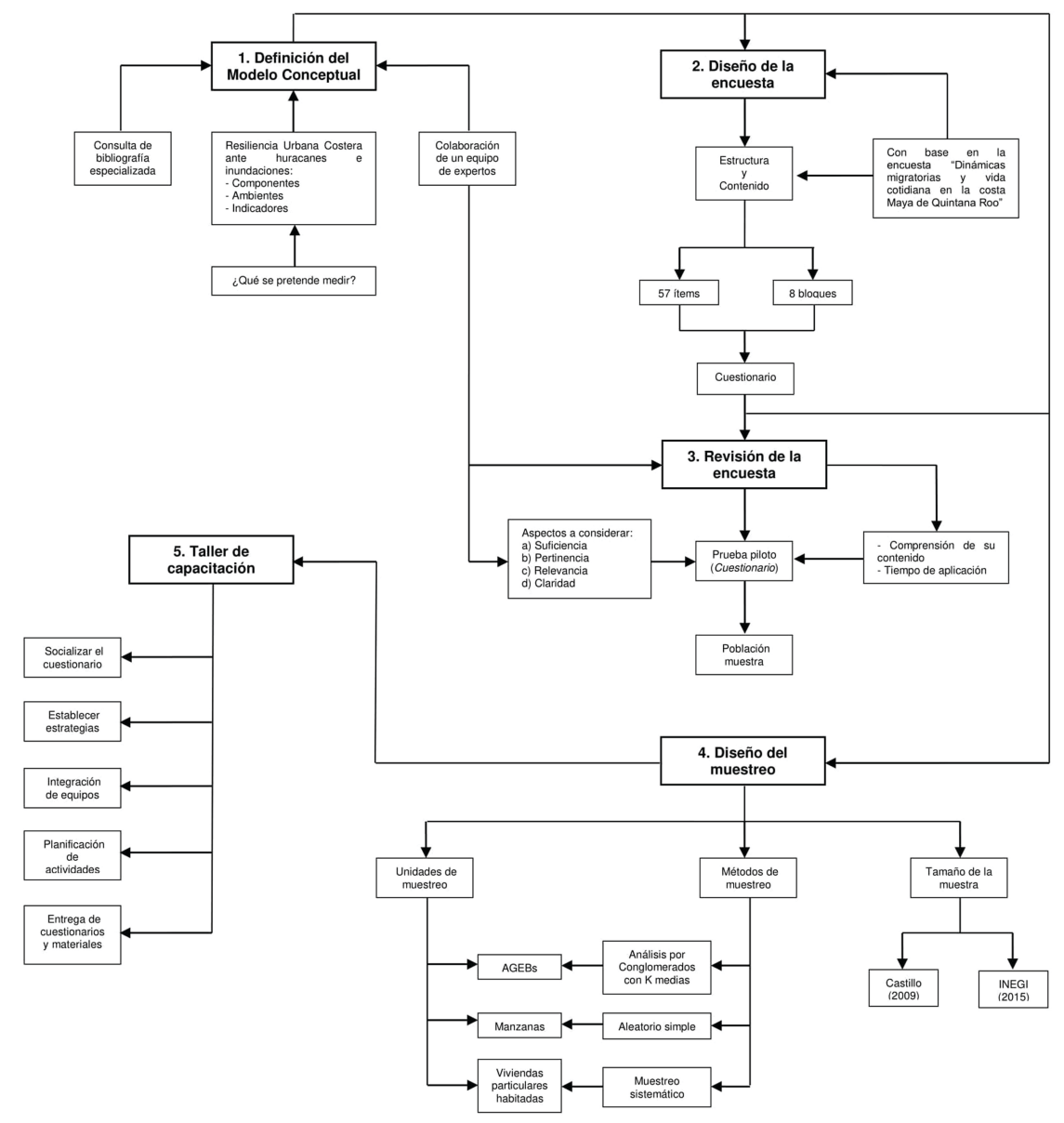

Figura 2. Etapas del diseño, elaboración e implementación de la encuesta Fuente: Autores, 2019.
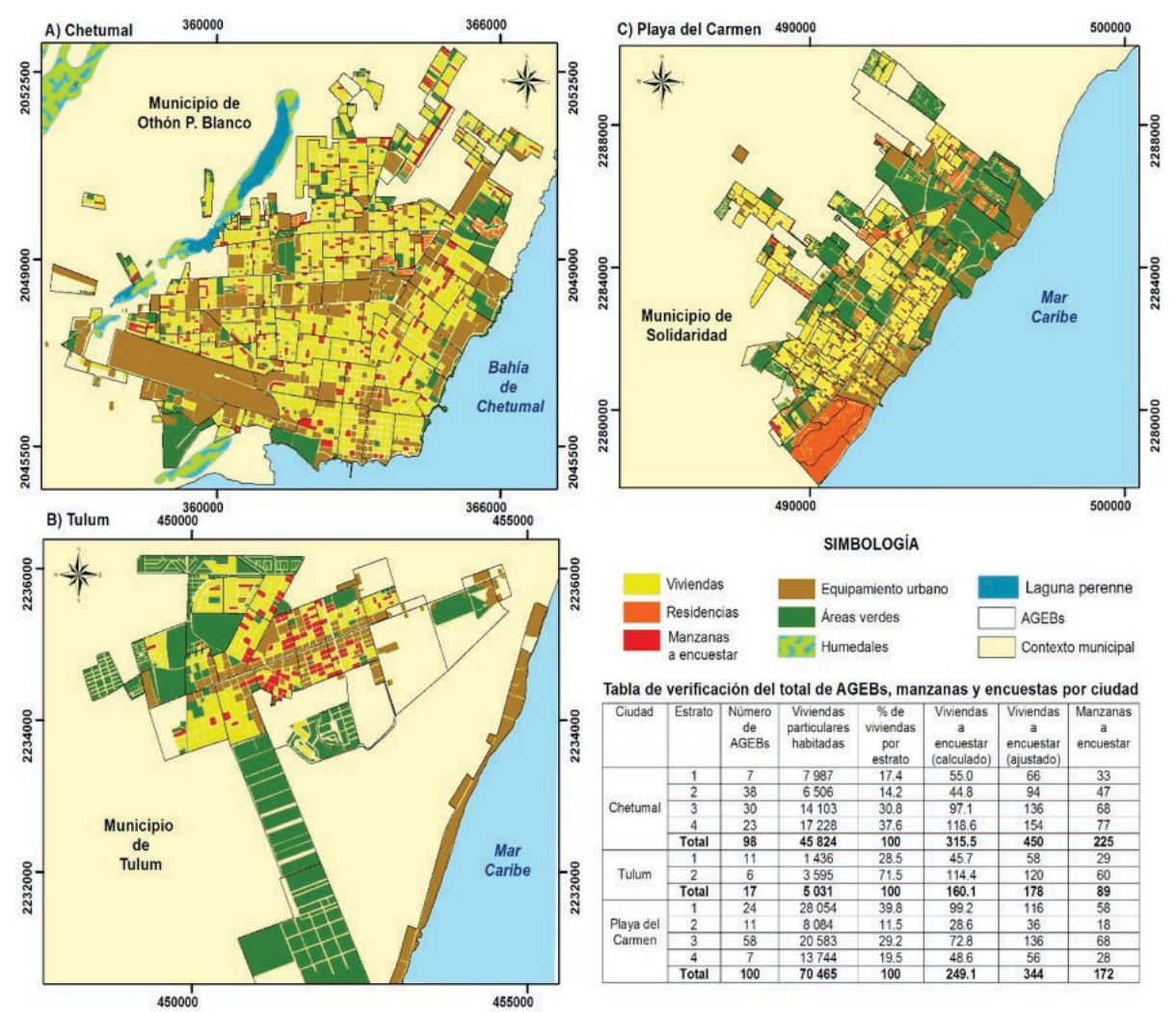

Tabla de verificación del total de AGEBs, manzanas y encuestas por ciudad \begin{tabular}{|l|l|l|l|l|l|l|}
\hline Ciudad Estrato Número Viviendas $\%$ de & Vivendas & Viviendas \\
\hline
\end{tabular}

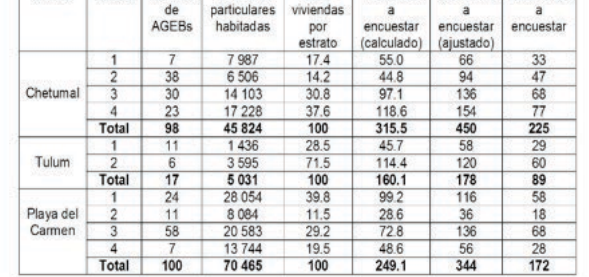

Figura 3. Distribución espacial de manzanas del estudio

Fuente: Autores, 2019, con base en INEGI (2016) e imágenes de satélite GeoEye-1, WordView-2 y WorldView-3 del año 2015. 
La siguiente figura muestra la representación espacial de las manzanas a encuestar $(10,15$, 16, 20 y 26) en campo del AGEB 0392 (Figura 4A). En la manzana 10 se aplicó la primera encuesta en la porción noreste y la segunda a nueve viviendas de la primera (valor de $\mathrm{K}$ ), debido a que en campo se observaron un total de 18 viviendas en la manzana (Figura $4 \mathrm{~b}$ ). Sin embargo, por circunstancias ajenas al encuestador se aplicaron encuestas en viviendas y manzanas contiguas alternas $(5,6,11$ o 17) a las seleccionadas inicialmente, pero dentro del mismo AGEB (0392), esto con la finalidad de cumplir con el total de viviendas a encuestar (Figura 4C). Los cambios se registraron tanto en el mapa como en las tablas de verificación.
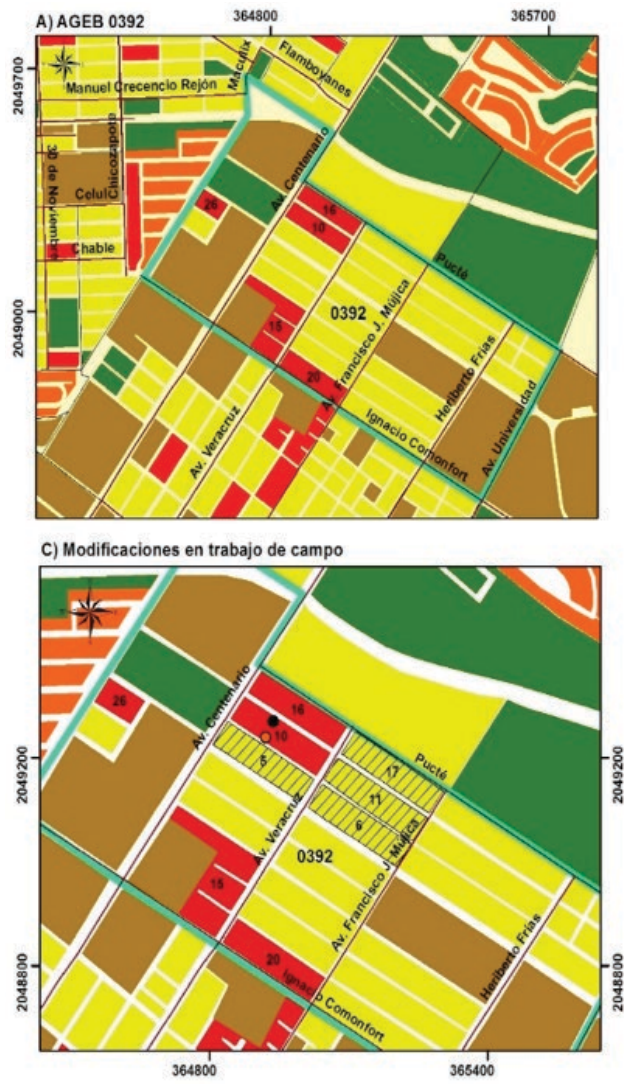

Figura 4. Diseño muestral por AGEB (ciudad de Chetumal) Fuente: Autores, 2019, con base en imágenes GeoEye-1 del año 2015.
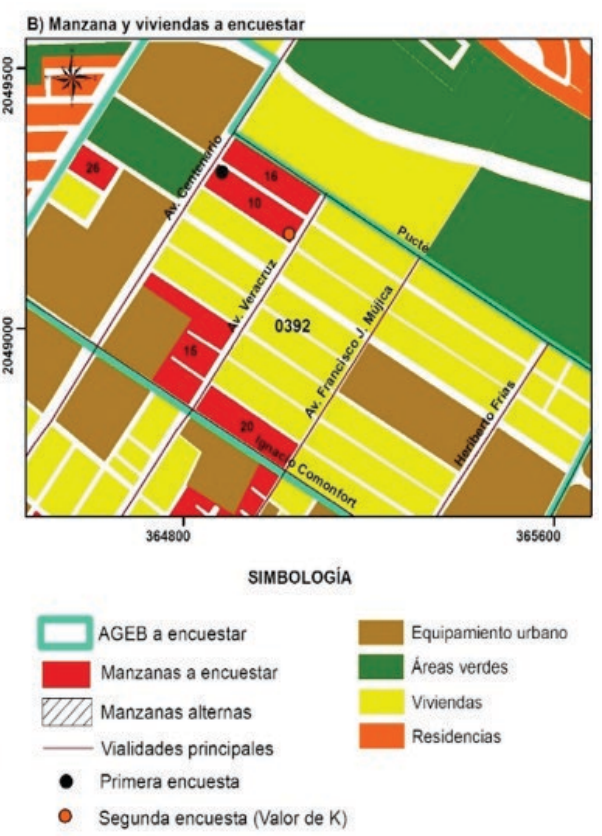

Tabla de verificación de las manzanas a encuestar por AGEB

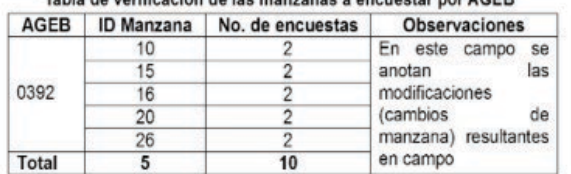

La Tabla 3 muestra el plan de trabajo implementado en este estudio para la aplicación de las encuestas en cada ciudad y en las figuras 5, 6 y 7 se puede observar la organización espacial del trabajo de campo por equipo en cada ciudad.

\begin{tabular}{|c|c|c|c|c|c|c|c|c|c|c|c|c|c|c|c|c|c|c|c|c|}
\hline & \multicolumn{20}{|c|}{ Chetumal } \\
\hline & \multicolumn{5}{|c|}{$10 / 05 / 2017$} & \multicolumn{5}{|c|}{$11 / 05 / 2017$} & \multicolumn{5}{|c|}{$16-19 / 05 / 2017$} & \multicolumn{5}{|c|}{ Total } \\
\hline & $E_{1}$ & $E_{2}$ & $E_{3}$ & \multicolumn{2}{|c|}{ Tot } & $E_{1}$ & $E_{2}$ & $E_{3}$ & \multicolumn{2}{|c|}{ Tot } & $E_{1}$ & $E_{2}$ & $E_{3}$ & \multicolumn{2}{|c|}{ Tot } & $E_{1}$ & $E_{2}$ & $E_{3}$ & \multicolumn{2}{|c|}{ Tot } \\
\hline $\mathrm{Nm}$ & 18 & 12 & 19 & \multicolumn{2}{|c|}{49} & 39 & 41 & 35 & \multicolumn{2}{|c|}{115} & 21 & 21 & 19 & \multicolumn{2}{|c|}{61} & 78 & 74 & 73 & \multicolumn{2}{|c|}{225} \\
\hline $\mathrm{Ne}$ & 36 & 24 & 38 & \multicolumn{2}{|c|}{98} & 78 & 82 & 70 & \multicolumn{2}{|c|}{230} & 42 & 42 & 38 & \multicolumn{2}{|c|}{122} & 156 & 148 & 146 & \multicolumn{2}{|c|}{450} \\
\hline & \multicolumn{20}{|c|}{ Playa del Carmen } \\
\hline & \multicolumn{5}{|c|}{$22 / 05 / 2017$} & \multicolumn{5}{|c|}{$23 / 05 / 2017$} & \multicolumn{5}{|c|}{$24-19 / 05 / 2017$} & \multicolumn{5}{|c|}{ Total } \\
\hline & $E_{1}$ & $E_{2}$ & $E_{3}$ & $E_{4}$ & Tot & $E_{1}$ & $E_{2}$ & $E_{3}$ & $E_{4}$ & Tot & $E_{1}$ & $E_{2}$ & $E_{3}$ & $E_{4}$ & Tot & $E_{1}$ & $E_{2}$ & $E_{3}$ & $E_{4}$ & Tot \\
\hline $\mathrm{Nm}$ & 10 & 11 & 11 & 15 & 47 & 28 & 16 & 22 & 21 & 87 & 7 & 11 & 10 & 10 & 38 & 45 & 38 & 43 & 46 & 172 \\
\hline \multirow[t]{4}{*}{\begin{tabular}{|l|}
$\mathrm{Ne}$ \\
\end{tabular}} & 20 & 22 & 22 & 30 & 94 & 56 & 32 & 44 & 42 & 174 & 14 & 22 & 20 & 20 & 76 & 90 & 76 & 86 & 92 & 344 \\
\hline & \multicolumn{20}{|c|}{ Tulum } \\
\hline & \multicolumn{5}{|c|}{$25 / 05 / 2017$} & \multicolumn{5}{|c|}{$26 / 05 / 2017$} & \multicolumn{5}{|c|}{ Total } & & & & & \\
\hline & $E_{1}$ & $E_{2}$ & $E_{3}$ & To & & $E_{1}$ & $E_{2}$ & $E_{3}$ & $T$ & ot & $E_{1}$ & $E_{2}$ & $E_{3}$ & To & & & & & & \\
\hline $\mathrm{Nm}$ & 12 & 12 & 16 & 40 & & 20 & 17 & 12 & 4 & 19 & 32 & 29 & 28 & 85 & & & & & & \\
\hline $\mathrm{Ne}$ & 24 & 24 & 32 & 80 & & 40 & 34 & 24 & 9 & 8 & 64 & 58 & 56 & 17 & & & & & & \\
\hline
\end{tabular}

$\mathrm{Nm}=$ Número de manzanas; $\mathrm{Ne}=$ Número de encuestas; El= Equipo 1; E2= Equipo 2; E3= Equipo 3; E4= Equipo 4; Tot= Total.

Tabla 3. Plan de trabajo de campo por equipo en cada ciudad

Fuente: Autores, 2019. 

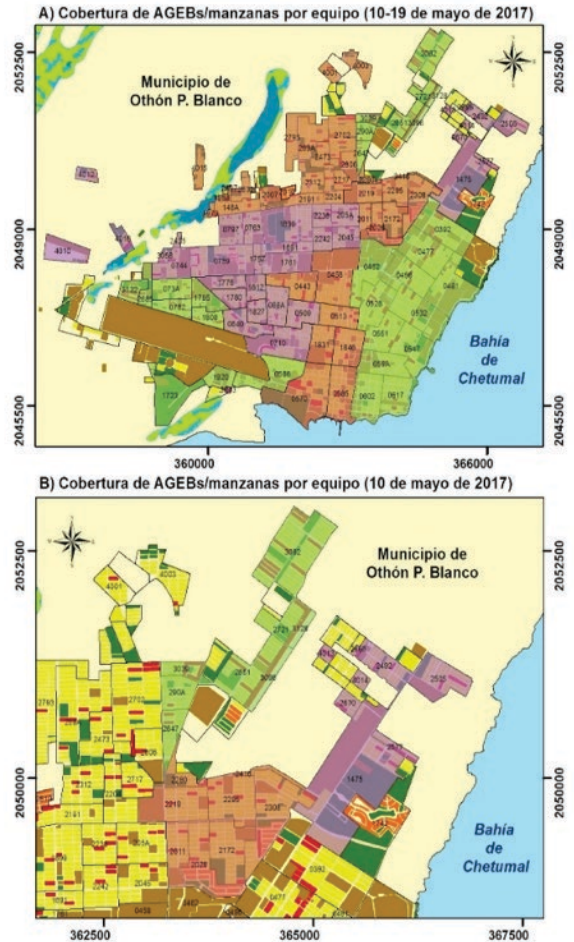

Figura 5. Organización espacial del trabajo de campo en Chetuma Fuente: Autores, 2019, con base en imágenes GeoEye-1 del año 2015.

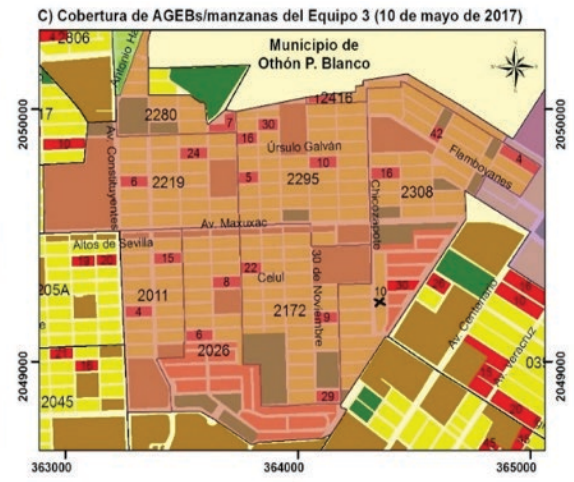

SIMBOLOGIA

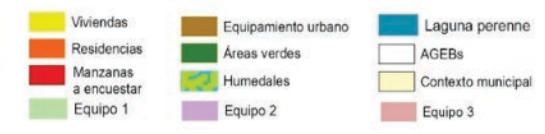

Tabla de verificación de AGEBs, manzanas y encuestas del Equipo 3 \begin{tabular}{|l|l|l|l|l|}
\hline Equipo & AGEB & ID Manzanas & $\begin{array}{c}\text { Mumero } \\
\text { manzanas }\end{array}$ & $\begin{array}{c}\text { Numero } \\
\text { encuestas }\end{array}$ \\
\hline
\end{tabular}

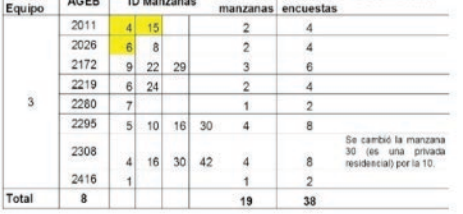

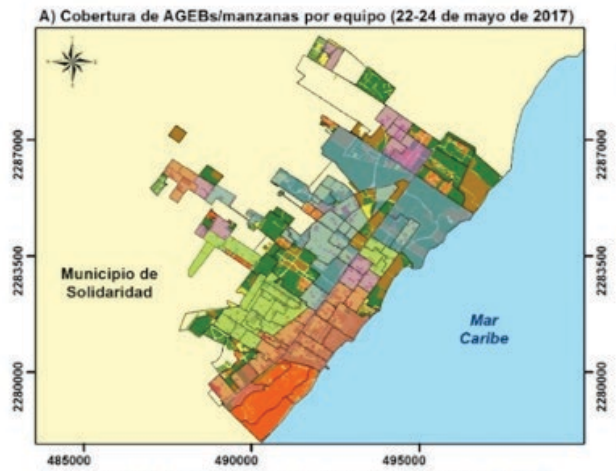
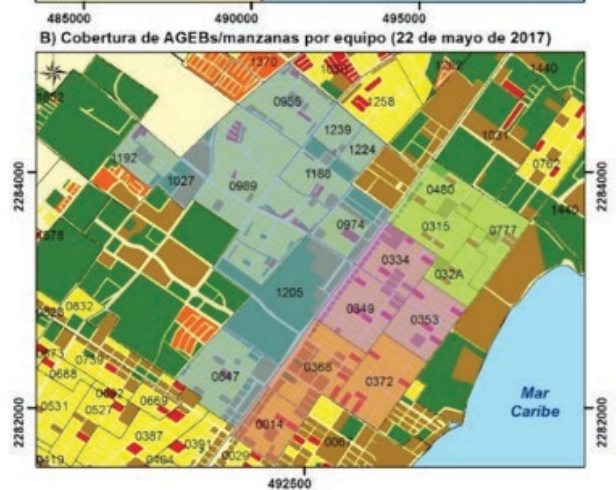

Figura 6. Organización espacial del trabajo de campo en Playa del Carmen Fuente: Autores, 2019, con base en imágenes WorldView-3 del año 2015.
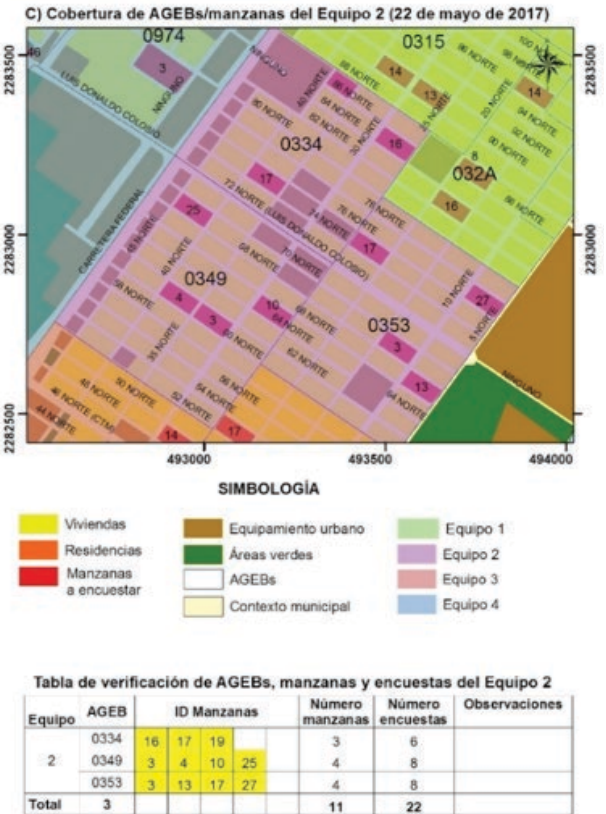

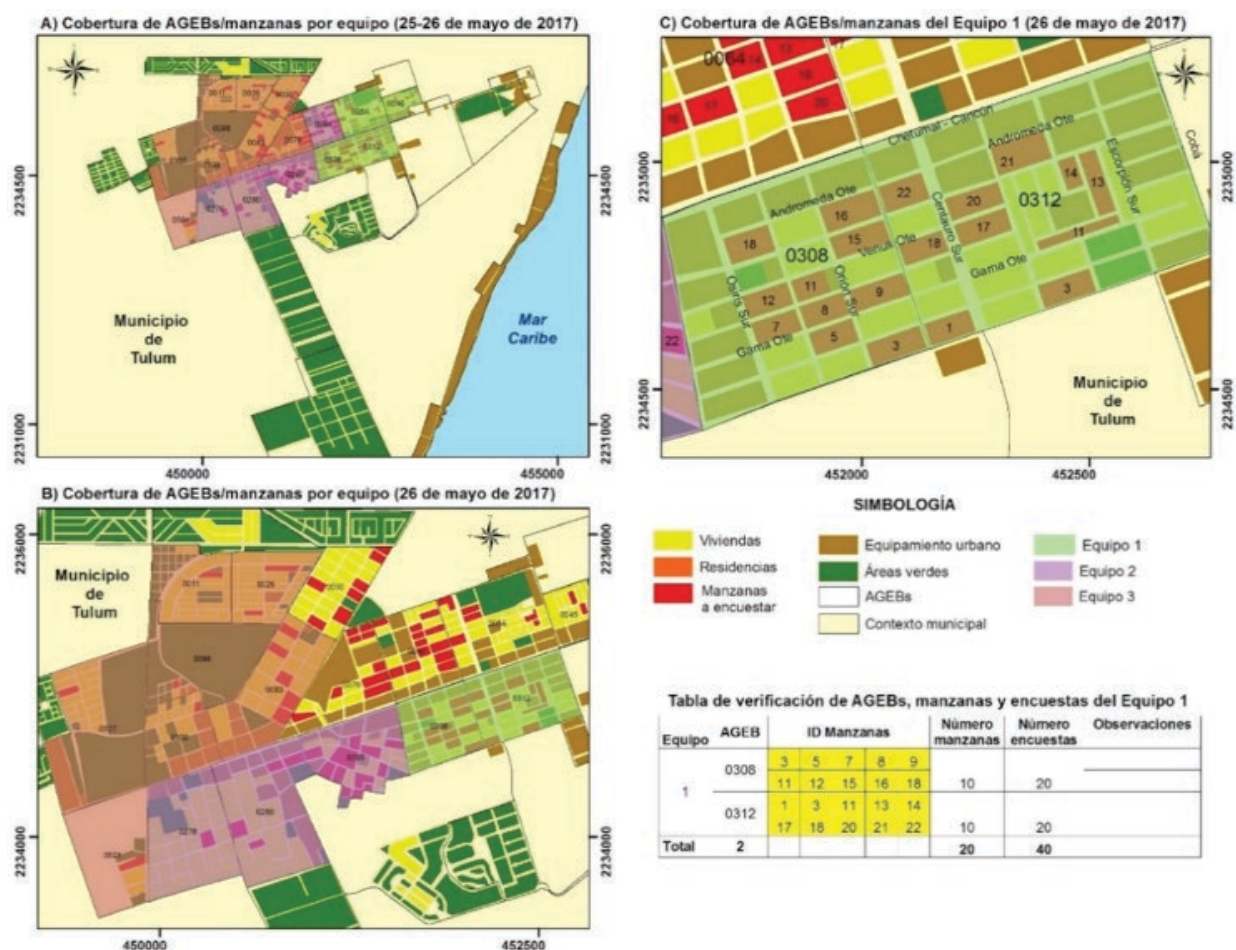

Figura 7. Organización espacial del trabajo de campo en Tulum Fuente: Autores, 2019, con base en imágenes WorldView-2 del año 2015.

\section{RESULTADOS}

\section{Modelo conceptual}

El modelo está integrado por tres componentes principales: a) Amenaza, b) Vulnerabilidad, y c) Capacidad de Adaptación. El primero corresponde a los fenómenos hidrometeorológicos que ocasionan desastres en las ciudades costeras del Caribe Mexicano; el segundo comprende los ambientes natural, social, económico, institucional, cultural y construido (viviendas) de cada ciudad; es decir, hace referencia a las características que determinan la susceptibilidad de los espacios urbanos costeros ante la ocurrencia de un huracán o inundación; y el tercero está constituido por las mismos ambientes del componente vulnerabilidad, sólo que se diferencian de estos porque hacen alusión a las capacidades que tienen las ciudades costeras para enfrentarse y adaptarse a los efectos de los fenómenos hidrometeorológicos. Los diferentes ambientes se desarrollan a continuación.

i) Ambiente natural. Hace referencia a los factores y elementos ambientales a considerar para la prevención y mitigación del riesgo de desastres ante la ocurrencia de fenómenos hidrometeorológicos (tormentas tropicales, huracanes, inundaciones). Entre estos se encuentran las condiciones edafológicas, geológicas, topográficas, hidrológicas, climáticas y de vegetación que caracterizan a las ciudades costeras del Caribe Mexicano.

ii) Ambiente social. Resulta importante conocer la situación actual y la dinámica demográfica de las ciudades costeras previo a la ocurrencia de un huracán o inundación, esto con el propósito de identificar los grupos de población vulnerables y sus necesidades, así como los grupos de apoyo que pueden colaborar, de manera conjunta con las autoridades en las actividades de prevención, reducción, respuesta, rehabilitación, recuperación y reconstrucción ante el riesgo de un desastre.

iii) Ambiente económico. En éste se enmarcan las condiciones económicas de la población que juegan un papel importante tras el paso de un huracán o inundación, pues de acuerdo con especialistas en el tema la población más vulnerable es aquella que no puede hacer frente a su recuperación (Cutter et al., 2003). 
iv) Construido. Considerar los equipamientos y la infraestructura crítica que responde a las necesidades básicas de la población es fundamental para evitar, en la medida de lo posible, un desastre que conlleve a pérdidas económicas y humanas. Se recomienda la necesidad de contar con hospitales, clínicas de especialidad, lugares que sirvan de refugios, vías de comunicación que permitan la evacuación de la población, y evitar la proliferación de viviendas construidas con materiales precarios, pues estos pueden convertirse en residuos que pueden favorecer a la amenaza (inundaciones).

v) Institucional. Las acciones o estrategias que instrumentan las autoridades y responsables de la gestión del riesgo de desastre deben ser incluyentes, es decir, se requiere de la participación social, académica y empresarial para la toma de decisiones. En este rubro se consideran los instrumentos de planeación, los atlas de riesgo, la legislación y normatividad en materia de riesgos, y los planes y programas de prevención y mitigación del riesgo de desastres.

vii) Cultural. Las experiencias vividas ante las amenazas y la forma en que se relaciona la población con su entorno son indispensables para la prevención y respuesta ante desastres por huracanes e inundaciones.

Por último, el modelo también considera una dimensión espacio-temporal, debido a que todo hecho o fenómeno ocurre en un determinado espacio y tiempo dado (Figura 8).

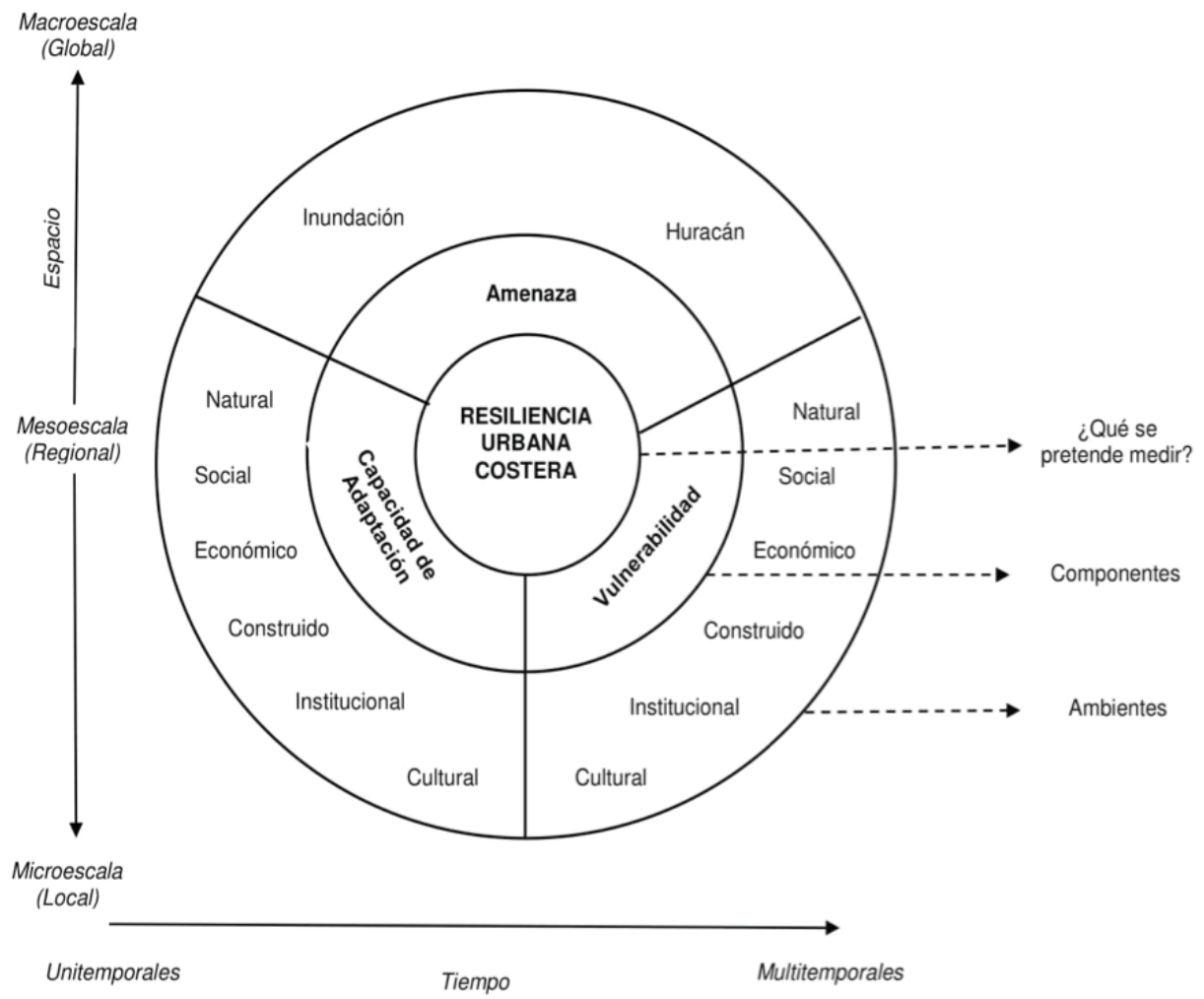

Figura 8. Modelo conceptual de resiliencia urbana costera Fuente: Autores, 2019.

\section{Indicadores de resiliencia urbana}

A pesar de que la mayoría de los habitantes de Chetumal, Tulum y Playa del Carmen tienen conocimiento que su ciudad es afectada por la ocurrencia de huracanes, más del $50 \%$ de la población que integra a estas ciudades no ha vivido la experiencia de un huracán. Lo que resulta alarmante es que, sólo el 29\%, 24\% y 30\% de las viviendas particulares de Chetumal, Tulum y Playa del Carmen, respectivamente, han recibido capacitación sobre qué hacer en caso de una inundación o huracán. Aunado a esto, el $56 \%$ de la población de Chetumal conocen programas de prevención de riesgos ante huracanes e inundaciones, el $32 \%$ corresponde a los habitantes de Tulum y el $36 \%$ concierne a la población de Playa del Carmen.

Es de resaltar que menos del $50 \%$ de la población que residen en estas tres ciudades costeras tiene conocimiento que su vivienda se encuentra ubicada en una zona inundable o que puede ser afectada por un huracán. Esta situación se agrava debido a que es mínimo el porcentaje de 
viviendas aseguradas ante estos fenómenos hidrometeorológicos. Para el caso de Chetumal y Playa del Carmen, las viviendas se inundan por la marea de tormenta que ocasionan los huracanes; sin embargo, existen viviendas que se inundan a causa de precipitaciones atípicas, por la falta de drenaje pluvial y el deterioro del mismo, a esto se suman las condiciones edafológicas (suelos litosoles), geológicas (rocas calizas) y de relieve (planicie) que favorecen a las inundaciones. Esto último ocurre con las viviendas que se inundan en Tulum.

Respecto al porcentaje de población que conoce la ubicación del refugio temporal más cercano a su vivienda, se observa que las ciudades de Chetumal y Tulum registran un mayor porcentaje (68\% y $67 \%$, respectivamente) en comparación con Playa del Carmen (56\%). La socialización de estos sitios es parte de las actividades y compromisos que compete a las autoridades responsables de la gestión del riesgo de desastres, principalmente a la Coordinación Estatal de Protección Civil (COEPROC) que a través de su página web comparte el listado de los albergues y refugios anticiclónicos de cada uno de los municipios que integran a Quintana Roo. A pesar de que más del $50 \%$ de los habitantes que residen en estas ciudades ubican los refugios, son pocos los que conocen las rutas de evacuación ante el riesgo de un huracán o inundación (31\% de la población de Chetumal y Tulum y $23 \%$ de la población de Playa del Carmen).

EI COEPROC aún necesita realizar esfuerzos de manera conjunta con la población que reside en estas ciudades, principalmente para que comiencen a diseñar un plan de emergencia familiar ante una contingencia hidrometeorológica, en Chetumal sólo el $48 \%$ de las viviendas cuentan con éste. En Tulum y Playa del Carmen más del $60 \%$ de las viviendas tienen un plan de emergencia familiar.

Otro aspecto importante que se obtuvo de la encuesta fue el porcentaje de viviendas en donde dos o más habitantes trabajan; para Chetumal se registró $40 \%$, Tulum $41 \%$ y Playa del Carmen $48 \%$. La capacidad o posibilidad económica es fundamental, sobre todo en las etapas de rehabilitación y reconstrucción ante un desastre por huracán o inundación. Cabe resaltar que los habitantes tienen empleos flotantes por temporadas y existe una falta de diversidad en cuanto a las actividades económicas que predominan en estas ciudades costeras (turismo en Playa del Carmen y Tulum, y en Chetumal destacan los servicios de gobierno por ser la capital del Estado) (Tabla 4).

\begin{tabular}{|c|c|c|c|}
\hline Indicador & Chetumal & Tulum & Playa del Carmen \\
\hline \% de población que no ha vivido la experiencia de un huracán & 53 & 63 & 63 \\
\hline$\%$ de población que desconoce que la ciudad es afectada por huracanes & 3 & 7 & 8 \\
\hline $\begin{array}{l}\text { \% de población que tiene conocimiento que su vivienda está ubicada en } \\
\text { una zona de inundación o que puede ser afectada por un huracán. }\end{array}$ & 48 & 41 & 39 \\
\hline$\%$ de viviendas que cuentan con un plan de emergencia familiar & 48 & 67 & 64 \\
\hline$\%$ de viviendas aseguradas ante huracanes e inundaciones & 7 & 7 & 13 \\
\hline$\%$ de viviendas en donde dos o más trabajan & 40 & 41 & 48 \\
\hline $\begin{array}{l}\text { \% de viviendas que han recibido capacitación sobre qué hacer en caso de } \\
\text { huracán o inundación }\end{array}$ & 29 & 24 & 30 \\
\hline $\begin{array}{l}\% \text { de población que conoce programas de prevención de riesgos ante } \\
\text { huracanes e inundaciones }\end{array}$ & 56 & 32 & 36 \\
\hline $\begin{array}{l}\% \text { de población que conoce la ubicación del refugio temporal más cercano } \\
\text { a su vivienda }\end{array}$ & 68 & 67 & 56 \\
\hline Población que conoce las rutas de evacuación ante huracán o inundación & 31 & 31 & 23 \\
\hline
\end{tabular}

Tabla 4. Indicadores de resiliencia urbana

Fuente: Autores, 2019, con base en trabajo de campo en el 2017.

\section{CONCLUSIONES}

El modelo conceptual fue la base fundamental para definir la información que se recopiló en campo, pues a partir de éste se plantearon las preguntas de la encuesta, desde luego, alineadas a lo que se pretende medir (resiliencia urbana costera ante huracanes e inundaciones). Este modelo se puede replicar en otras áreas geográficas costeras, que están expuestas al riesgo de desastres por la ocurrencia de un huracán o inundación. Si se desea aplicar esta metodología en otras urbes, 
será indispensable una discusión previa sobre los indicadores de amenaza y vulnerabilidad social que se pretendan considerar.

El proceso de revisión de la encuesta, por parte del grupo de expertos, fue importante para la mejora del instrumento de recolección de datos, principalmente contribuyó a la comprensión del contenido del cuestionario y a optimizar el tiempo de aplicación. La recopilación de información en campo fue exitosa debido a la planificación de las actividades y a las estrategias sugeridas en el taller de capacitación. El principal insumo que permitió a reducir los costos que implica el trabajo de campo, así como el periodo de aplicación de la encuesta fue la cartografía de la cobertura espacial por equipo con su respectiva jornada de trabajo.

La elaboración de una cartografía urbana a nivel de ciudad contribuyé a la toma de decisiones en cuanto a la gestión del riesgo de desastres, siendo tal vez más funcional a nivel de barrios. Además, datos a nivel local evidencian la presencia de grupos de vulnerabilidad por edad y género.

Consideramos que la metodología descrita en este trabajo es pertinente para el análisis y evaluación de datos asociados con la resiliencia, la vulnerabilidad y el riesgo de desastres, esto mediante el cálculo de indicadores locales pertinentes y explicativos. Además, está sujeta a modificaciones y puede adaptarse a diversos contextos y escalas geográficas en áreas de costa, desde luego, ajustándose a los objetivos que se pretenden alcanzar.

Una de las limitaciones de este estudio fue la ausencia de datos de las viviendas particulares habitadas ubicadas en zonas residenciales. Esta información se considera importante, pues se desconoce si las personas que habitan estos espacios han vivido alguna experiencia relacionada con la ocurrencia de huracanes e inundaciones y si están capacitados para enfrentar estas amenazas, ya que se considera que la vulnerabilidad social no tiene una relación directa con la pobreza, por lo que información respecto cómo los grupos demográficos de una ciudad crean sus procesos de adaptación apoyaría las acciones hacia la resiliencia. Incluso, en los fraccionamientos residenciales, las problemáticas serían distintas, los grupos vulnerables pueden ser las personas del servicio y los adultos mayores que viven solos.

\section{AGRADECIMIENTOS}

Este estudio se desarrolló en el marco del proyecto "Resiliencia en ciudades costeras del Caribe Mexicano ante desastres por huracanes: Chetumal, Tulum y Playa del Carmen", financiado por el Consejo Nacional de Ciencia y Tecnología (CONACYT), en atención a la Convocatoria de Proyectos de Desarrollo Científico para atender Problemas Nacionales 2014. Los autores agradecen a los profesores - investigadores que colaboraron en el proyecto referido; a los estudiantes de la Universidad de Quintana Roo por su valiosa participación en la aplicación de las encuestas y, desde luego, a los habitantes de las ciudades de Chetumal, Tulum y Playa del Carmen por proporcionar la información referente a los cuestionarios.

\section{RECONOCIMIENTO}

A la Dra. Lourdes Castillo Villanueva (finada) por su esfuerzo, dedicación y colaboración en este trabajo. En su memoria.

\section{REFERENCIAS}

Academia Nacional de Investigación y Desarrollo A.C. (2013a). Propuesta de Programa de Adaptación ante la Variabilidad Climática y el Cambio Climático del Sector Turismo en Cancún, Quintana Roo. México: A.C.

Academia Nacional de Investigación y Desarrollo A.C. (2013b). Propuesta de Programa de Adaptación ante la Variabilidad Climática y el Cambio Climático del Sector Turismo en la Rivera, Maya: Solidaridad, Quintana Roo. México: A.C.

Academia Nacional de Investigación y Desarrollo A.C. (2013c). Propuesta de Programa de Adaptación ante la Variabilidad Climática y el Cambio Climático del Sector Turismo en la Rivera, Maya: Tulum, Quintana Roo. México: A.C.

Adger, W., Arnell, N., \& Tompkins, E. (2005). Successful adaptation to climate change across scales. Global Environmental Change, 15(2), 77-86.

Castillo, L. (2009). Urbanización, problemas ambientales y calidad de vida urbana. México, Distrito Federal: Plaza \& Valdés.

Christmann, G., Ibert, O., Kilper, H., \& Timothy M. (2012). Vulnerability and Resilience from a SocioSpatial Perspective. Towards a Theoretical Framework. Working Paper $N^{\circ} 45$. Erkner, Germany: Leibniz Institute for Regional Development \& Structural Planning. 
Comisión Intersecretarial de Cambio Climático. (2012). Adaptación al Cambio Climático en México: Visión, Elementos y Criterios para la Toma de Decisiones. México: SEMARNAT, INECC.

Coordinadora Nacional para la Reducción de Desastres CONRED. (2015). Indicadores mínimos para la construcción de la resiliencia de los municipios de Guatemala. Ciudad de Guatemala: CONRED.

Cutter, S., Boruff, B., \& Shirley, W. (2003). Social vulnerability to environmental hazards. Social Science Quarterly, 2(84), 242-261.

Cutter, S., Barnes, L., Berry, M., Burton, C., Evans, E., Tate, E., \& Webb, J. (2008). A place-based model for understanding community resilience to natural disasters. Global Environmental Change, 18(4), 598-606.

Cutter, S., Ash, K., \& Emrich, C. (2014). The geographies of community disaster resilience. Global Environmental Change, 29, 65-77.

Estrategia Internacional para la Reducción de Desastres de las Naciones Unidas UNISDR. (2009). Terminología sobre el Reducción del Riesgo de Desastres. Ginebra: UNISDR.

Fernández, M. (2015). La resiliencia urbana, clave del futuro de las ciudades. El País [Web]. Recuperado de http://elpais.com/elpais/2015/05/21/planeta_futuro/1432231832_145438.html [visitado o4 de agosto de 2019]

Galceran, M. (2015). La reducción del riesgo de los desastres Translación de la agenda global de resiliencia al ámbito local. Notes internacionales $C I D O B$ 117, 1-5.

Grothmann, T. \& Anthony, P. (2005). Adaptive capacity and human cognition: The process of individual adaptation to climate change. Global Environmental Change, 15(3), 199-213.

H. Congreso del Estado de Quintana Roo (2018). Ley de Asentamientos Humanos, Ordenamiento Territorial y Desarrollo Urbano del Estado de Quintana Roo. Chetumal: Congreso del Estado de Quintana Roo.

Gallopin, G.C. (2006). Linkages between vulnerability, resilience, and adaptive capacity. Global Environmental Change, 16(3), 293-303.

Ihl, T. \& Frausto, O. (2014). El Cambio Climático y los huracanes en la Península de Yucatán. En Frausto O. Monitoreo de riesgo y desastre asociados a fenómenos hidrometeorológicos y cambio climático. México: Universidad de Quintana Roo.

Intergovernmental Panel on Climate Change IPCC. (2014). Cambio climático 2014: Informe de síntesis. Contribución de los Grupos de trabajo I, II y III al Quinto Informe de Evaluación del Grupo Intergubernamental de Expertos sobre el Cambio Climático [Equipo principal de redacción, R.K. Pachauri y L.A. Meyer (eds.)]. Ginebra: IPCC.

Instituto Nacional de Estadística y Geografía INEGI. (2010). Censo de Población y Vivienda 2010. Principales resultados por AGEB y manzana urbana. México: INEGI.

Instituto Nacional de Estadística y Geografía INEGI. (2013). Censo de Población y Vivienda 2010. Perfil sociodemográfico: Estados Unidos Mexicanos. México: INEGI.

Instituto Nacional de Estadística y Geografía INEGI. (2015). Encuesta Intercensal 2015. Síntesis metodológica y conceptual. México: INEGI.

Instituto Nacional de Estadística y Geografía INEGI. (2016). Marco Geoestadístico - Datos Vectoriales. México: INEGI.

Jacobi, J., Schneider, M., Pillco Mariscal, M. I., Huber, S., Weidmann, S., \& Rist, S. (2014). La contribución de la producción del cacao orgánico a la resiliencia socio-ecológica en el contexto del cambio climático en el Alto Beni - La Paz. Acta Nova, 6(4), 351-383.

Janssens, M., Gaese, H., Keutgen, N., Ortega, R., Torrico, J. C. \& Pohlan, J. (2015). Integrating agricultural and environmental sustainability across generations: the never-ending quest for the Golden Fleece. Journal of Natural Resources and Development, 5, 17-28.

Jeans, H., Castillo, G.E. \& Thomas, S. (2017). L'avenir est un choix. Absorption, adaptation et transformation: Les capacités de résilience. Oxfam International [Web]. Recuperado de: https:// oxfamilibrary.openrepository.com/bitstream/handle/10546/620178/gd-resilience-capacities-absorbadapt-transform-250117-fr.pdf?sequence=6\&isAllowed=y [visitado 04 de agosto de 2019]

Lagares, P. \& Puerto, J. (2001). Población y muestra. Técnicas de muestreos. Management Mathematics for European Schools. España: Universidad de Sevilla.

Lavell, A. (1997). Viviendo en riesgo. Comunidades vulnerables y prevención de desastres en América Latina. Bogotá: Tercer Mundo. 
Lein, J.K. (2003). Integrated Environmental Planning. Singapur: Blackwell Science.

Martín, M. (2004). Diseño y validación de cuestionarios. Matronas Profesión, 5(17), 23-29.

Naciones Unidas UN. (1994). Decenio Internacional para la Reducción de los Desastres Naturales. Estrategia y Plan de Acción de Yokohama para un Mundo más Seguro. Kobe: UN.

Naciones Unidas UN. (2005). Informe de la Conferencia Mundial sobre la Reducción de los Desastres. Kobe, Hyogo: UN.

Naciones Unidas UN. (2012). Cómo desarrollar ciudades más resilientes. Un manual para los líderes de los gobiernos locales. Una contribución a la Campaña Mundial 2010-2015 "Desarrollando ciudades resilientes - ¡Mi ciudad se está preparando!”. Ginebra: UN.

Naciones Unidas UN. (2015). Marco de Sendai para la Reducción del Riesgo de Desastres 2015-2030. Sendai: UN.

Naciones Unidas (2017). Nueva Agenda Urbana. Quito, Ecuador: UN.

Norris, F., Stevens, S. Pfefferbaum, B., Wyche, K., \& Pfefferbaum, R. (20o8). Community Resilience as a Metaphor, Theory, Set of Capacities, and Strategy for Disaster Readinees. Am J Community Psychol, $41,127-150$.

UN-Habitat. (2017). Programa de Perfiles de Ciudades Resilientes. UN-Habitat [Web]. Recuperado de https://es.unhabitat.org/iniciativas-urbanas/iniciativas-programas/perfiles-ciudades-resilientes/ [visitado o4 de agosto de 2019]

Parsons, M., Glavac, S., Hastings, P., Marshall, G., McGregor, J., McNeill, J., Morley, P., Reeve, I. \& Stayner, R. (2016). Top-down assessment of disaster resilience: A conceptual framework using coping and adaptive capacities. International Journal of Disaster Risk Reduction, 19, 1-11.

Resilience Alliance. (2010). Assessing resilience in social-ecological systems: Woorbook for practitioners. Versión 2.o. Resilience Alliance [Web]. Recueprado de: http://www.resalliance. org/3871.php [visitado o4 de agosto de 2019]

Rockefeller Foundation-Arup RF-Arup. (2015). City Resilience Framework. New York: RF-Arup.

Salles de Almeida, P., Sara, C., Silva, R., \& Iturbe, A. (2007). Atlas de Riesgo Oceanográfico del Es $\neg$ tado Versión 2.o., Programa de Prevención y manejo de Recursos Naturales del estado de Quintana Roo. UNAM. Chetumal, México: DCI-UQROO,

Secretaría de Desarrollo Agrario, Territorial y Urbano SEDATU (2016). Guía de Resiliencia Urbana. México: SEDATU.

Secretaría de Medio Ambiente y Recursos Naturales. (2014). Versión de difusión del Programa Especial de Cambio Climático 2014-2018. México: Secretaría de Medio Ambiente y Recursos Naturales.

Sierra, L. (2014). Dinámicas migratorias y vida cotidiana en la Costa Maya de Quintana Roo. Mérida: Ediciones de la Calle 70.

Smith, G., Nandwani, D., \& Kankarla, V. (2016). Facilitating resilient rural-to-urban sustainable agriculture and rural communities. International Journal of Sustainable Development $\mathcal{E}$ World Ecology, 24(6), 485-501.

Torrico, J.C., \& Janssens, M.J. (2010). Rapid assessment methods of resilience for natural and agricultural systems. Anais da Academia Brasileira de Ciências, 82(4), 1095-1105.

Vidal, L. E. (2010). Análisis de capacidad de gestión ambiental ante el cambio climático en instrumentos de planeación en la costa de Quintana Roo. En E. Rivera, I. Azuz, L. Alpuche y G. Villalobos (Eds.), Cambio Climático en México: Un enfoque costero y marino (789-809 pp.). México: Universidad Autónoma de Campeche \& CETYS-Universidad. 